\title{
An ultra fast-acting electro-hydraulic digital valve and high-speed electro-hydraulic servo valves using multilayered PZT elements
}

\author{
Shinichi YOKOTA*, Kenichirou HIRAMOTO** \\ and Kotarou AKUTSU $\star \star$ \\ *Precision and Intelligence Laboratory \\ Tokyo Institute of Technology \\ Nagatsuta 4259, Midori-ku, Yokohama 227, Japan
}

\begin{abstract}
This paper deals with the development of two-type ultra high speed valves, one of them is a highspeed digital valve whose switching speed is within 100 microseconds, and the other is an ultrahigh-speed servo valve with the spool displacement of $30 \mu \mathrm{m}$ and the bandwidth over $5 \mathrm{kHz}$. In this study, commercially available multilayered piezo-devices are used to drive the coupled poppets of the digital valve and the spool of the servo valve directly. In the former one, by introducing a kind of feed forward control and employing some new methods, on-off-type coupled poppet valves with high-speed response to within 100 microseconds of switching speed are successfully developed. In the latter one, the hysteresis of the driving element of the valve is removed by introducing an inverse hysteresis element implemented on a microcomputers and operated in real time. As a result, a servo valve with the bandwidth over $5 \mathrm{kHz}$ is developed.
\end{abstract}

\section{KEYWORDS}

Fluid Power Systems, Electro-hydraulic, Servo Valve, Piezo-electric Device, Inverse Hysteresis, High Speed Response, Digital Valve, Poppet Type,

\section{INTRODUCTION}

In high-speed electrohydraulic servo control systems, servo valves are mainly used to drive actuators, and the limit of the response of the system is dependent on the servo valves. As is well known, servo valves play an important role in electro-hydraulic servo systems as an interface between electric signal and hydraulic power.
Piezoelectric devices have the potential to drive valves in quick response. However, the devices have the disadvantage of hysteresis between applied voltage and output displacement (force in strict sense). In this study, commercially available multilayered piezo-electric devices are used to drive the valves directly.

Concerning the problems in developing a high-speed digital valve, Tanaka[1] reported an on-off-type electromagnetic valve, and 
Lühmann[2] investigated the control valve using a PZT driving element with a switching time of $0.5 \mathrm{~ms}$. However, the valve was not sufficiently quick in response to develop a high-speed digital servo system.

With respect to analogue servo valves, Ohuchi, Nakano and Endou[3] developed servo valves using PMN electrostrictive elements with the bandwidth over $1.2 \mathrm{kHz}$. Ikebe and Nakada[4] developed a PWM drive servo valve using a PZT bimorph-type element.

There are following problems yet to be solved to develop a high-speed servo valve using multilayered PZT elements, as has been reported by Yokota, Akutsu and Hiramoto[5][6][7].

1) high-speed driving of the multilayered PZT elements as a large capacitance load.

2) cancellation of the hysteresis characteristics effects of the multilayered PZT elements.

3) improvement of the oscillatory transient response of the system.

The aims of this study are to propose a high-speed control method of valve poppet displacement, to develop a high-speed on-off valve whose switching time is within 100 microseconds, and in addition, to develop an ultra highspeed servo valve with the spool displacement of $30 \mu \mathrm{m}$ and the bandwidth over $5 \mathrm{kHz}$.

\section{AN ULTRA FAST-ACTING ELECTRO-HYDRAULIC DIGITAL VALVE}

In comparison with a spool-type valve, a poppet-type one has advantages for small valve displacement because the control valve is expected to have minimal leakage by pushing a poppet on the valve sheet.

Figure 1 shows the schematic view of the newly devised poppet-type on-off valve. The main feature of the valve is that a pair of onoff valves are connected face to face in a series. This structure is able to avoid the effects caused by supply pressure.

The multilayered PZT element used in this paper has following features. The schematic of the element is shown in Fig.2. The element is a type of ceramic which exhibits piezo effects

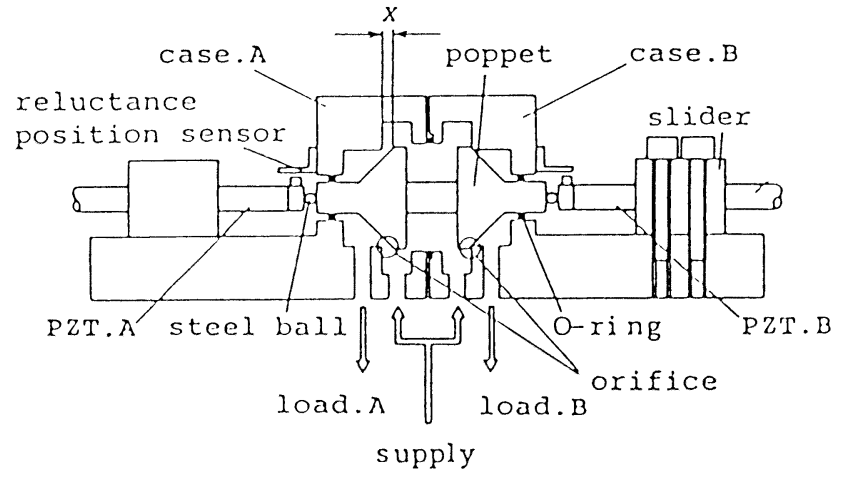

Fig.1 The configuration of a poppet-type on-off valve

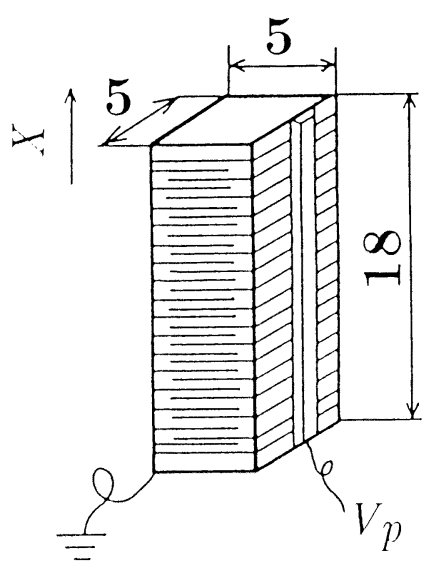

Fig.2 The form of a multilayered PZT element

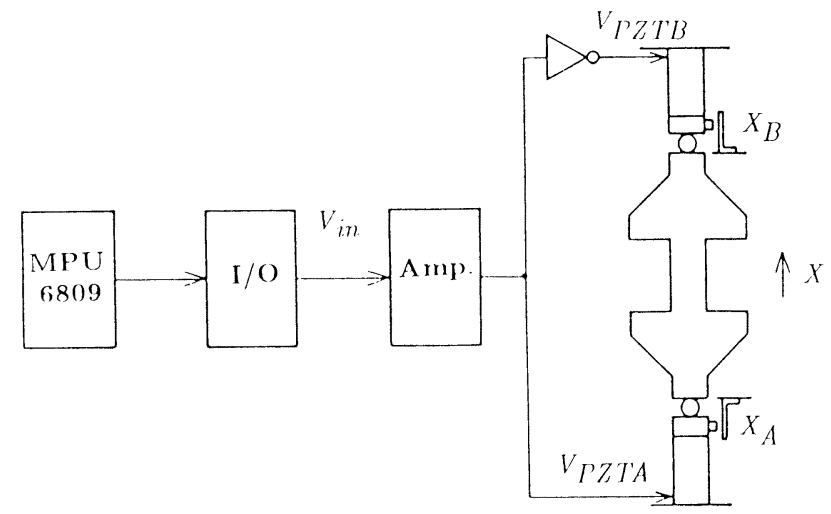

Fig.3 Driving system of poppet-type on-off valve

and expands 15 micrometers with no load by applying $100 \mathrm{~V}$, and the output force is $850 \mathrm{~N}$ maximum with no expansion. The element has comparatively large hysteresis characteristics between the applied voltage and the strain. In this case, the hysteresis will not affect the system in using on-off high-speed switching. 


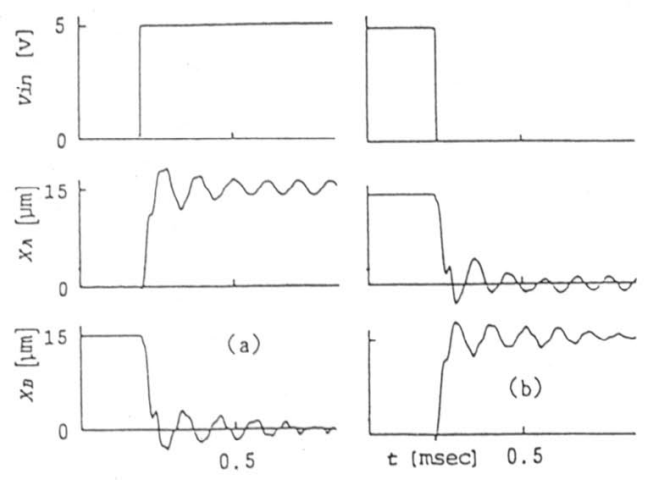

Fig.4 Recorded waveforms of poppet displacement

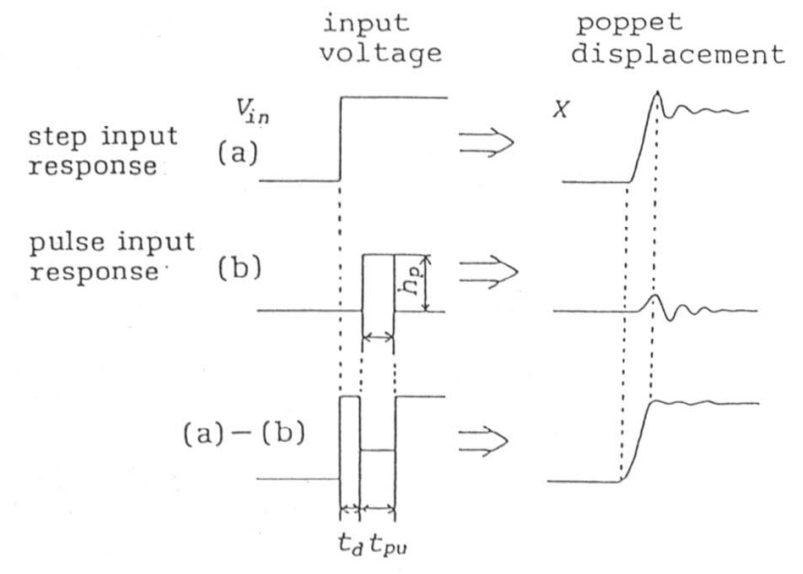

Fig.5 Principle of feedforward control

The poppet is driven by a pair of the multilayered PZT elements, in a push-pull differential drive style directly from both sides. Using these materials, we succeeded in obtaining $8.7 \mathrm{kHz}$ as the mechanical eigenfrequency of the valve system shown in Fig.3. The diameter d of the poppet is $20 \mathrm{~mm}$. Maximum flow rate through the orifice is $120 \mathrm{~cm}^{3} / \mathrm{s}$ at a pressure drop of $10 \mathrm{MPa}$.

\section{The driving system of the poppet}

The PZT elements have large capacitance as loads to control applied voltage. Their capacitance is 1.6 micro Farad each. In order to switch the valve opening actively in high speed,

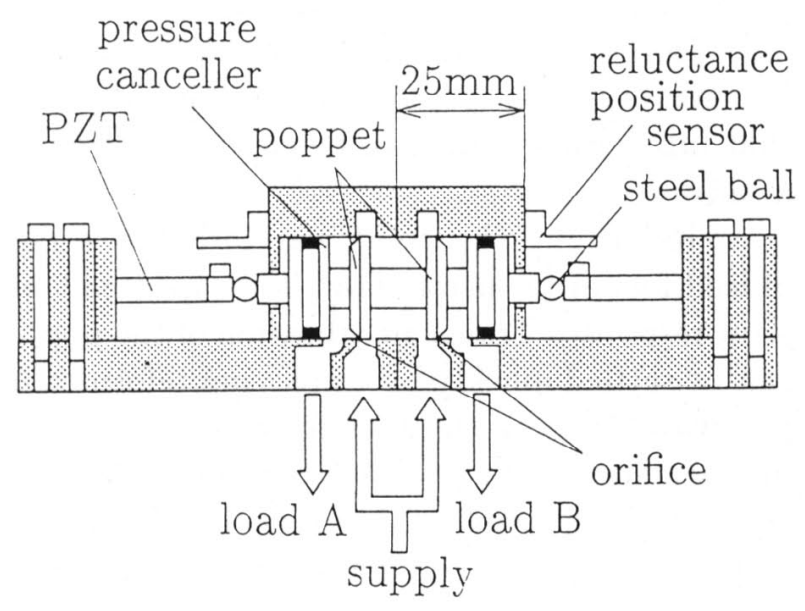

Fig.6 The configuration of a poppet-type on-off valve (with canceller)

the driving amplifier is required to have highspeed control capabilities and to actively generate a large amount of current.

In this paper, a new driving amplifier to charge and discharge actively and quickly is newly devised. A large-current-type NMOS FET is employed which has superior switching characteristics. As a result, fast response of the applied voltages is obtained, which rise from $0 \mathrm{~V}$ to $100 \mathrm{~V}$ in 24 microseconds and decreases in the same period. Figure 4 shows the results of step response of the poppet displacement. During this experiment, in order to observe easily the transient motion, the space between the poppet and the valve sheet is set much wider than 15 micrometers.

Figure 4(a) indicates recorded waveforms of the valve displacement (stepup) and Figure 4(b) shows the step-down ones. The recorded poppet displacements demonstrate very quick response in both directions within 60 microseconds; however, the results of the transient oscillation of the system suggest that the system damping is inadequate and too small.

Feed forward control for improving poppet transient response

As well as quick response, sufficient damp- 
ing which exhibits oscillatory transient response is necessary for the poppet system.

In the case of an on-off valve, there are only two states in the system, that is, on and off, so that input waveforms can be clearly determined in advance.

Reforming the input waveforms as a kind of feed forward control allows for improved transient response. Transient vibration of the poppet can be settled quickly by employing reformed input waveforms as the feed forward control in a manner similar to posicast control. The principle of the control is shown in Fig.5. In this method, the adjustable parameters are the time periods $t_{d}, t_{p u}$.

\section{A canceler for load pressure on the poppet}

In this paper, because of poppet valves being connected face to face in series, the fast acting on-off valve is not affected by the axial force due to supply pressure. However, as shown in Fig.1, the valve is subjected to the effect of the pressure difference between load pressures of both sides. The PZT elements could not control the poppet displacement at high pressure because of the axial force caused by the pressure. This makes it difficult to rise the supply pressure. In the case of the valve described in the previous section, the valve could not operate more than $1.7 \mathrm{MPa}$ of the supply pressure.

To solve this problem, we introduce a pressure canceler being attached to the poppets as shown in Fig.6. The shape of the orifice portion remains the same as the previous poppet. The mass of the poppet is much heavier $(0.022 \mathrm{~kg})$ by adding the canceler.

As a result, the eigen frequency of the mechanical poppet system reduces to $7 \mathrm{kHz}$ and the rise time for step wise input becomes $65 \mu \mathrm{s}$. Figure 7 shows the results of recorded wave forms of the poppet displacement with the pressure canceler, the results demonstrate that the poppet is able to follow $2 \mathrm{kHz}$ rectangular wave of an input. In this experiment, supply pressure is set at $5 \mathrm{MPa}$. The values of used parameters in this case are as follows, $t_{d}=11 \mu \mathrm{sec}, t_{p u}=45 \mu \mathrm{sec}$. It is ascertained that introducing the pressure canceler removes limitation on supply pressure from
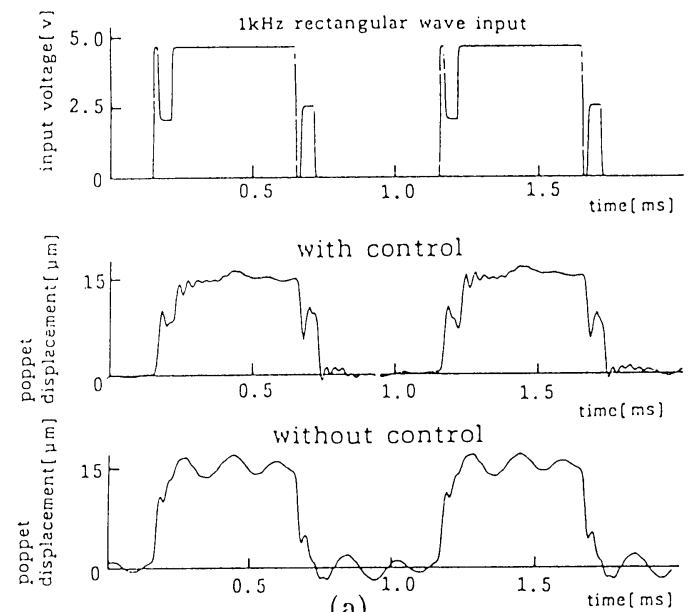

(a)
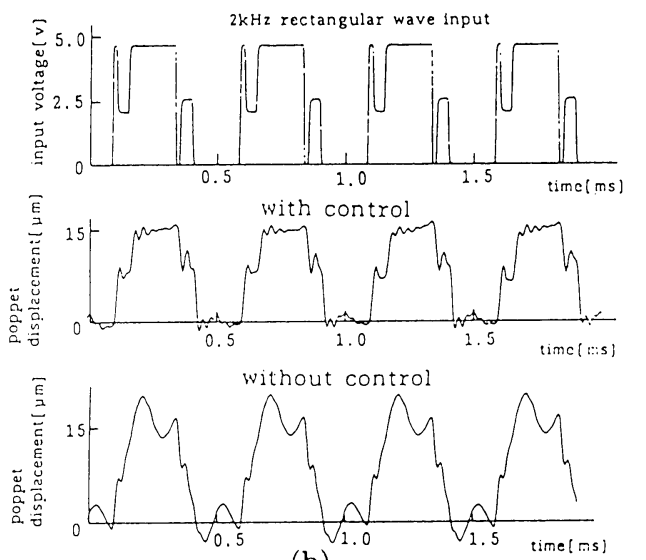

(b)

Fig.7 Rectangular wave input recorded waveforms of poppet displacement

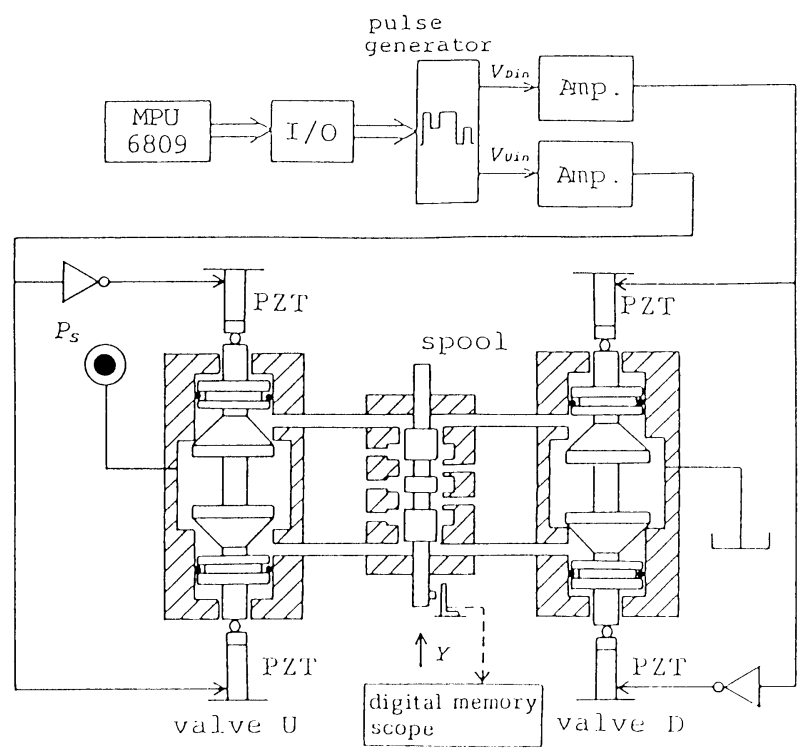

Fig. 8 Spool-type two-stage digital servo valve 
the poppet valve.

\section{A DIGITAL INPUT TWO STAGE SERVO VALVE}

Construction of two stage digital servo valve

A two-stage servo valve is investigated using these transducers which drive spool valve as a second stage in an application. Figure 8 shows the schematic diagram of the digital input servo valve devised in this paper.

In the computer system, $6809 \mathrm{CPU}$ is employed, and the output is fed to the electro-
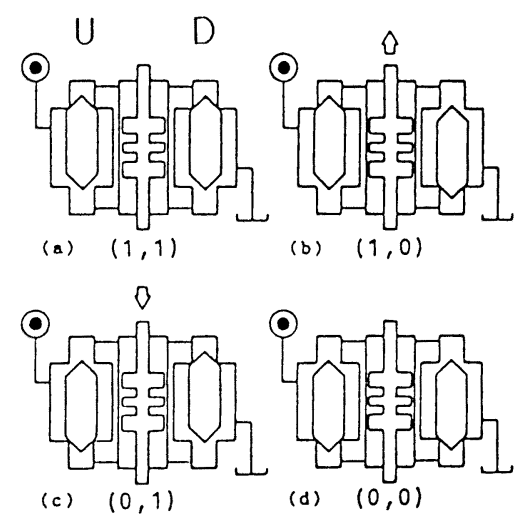

Fig.9 State combination of the transducers

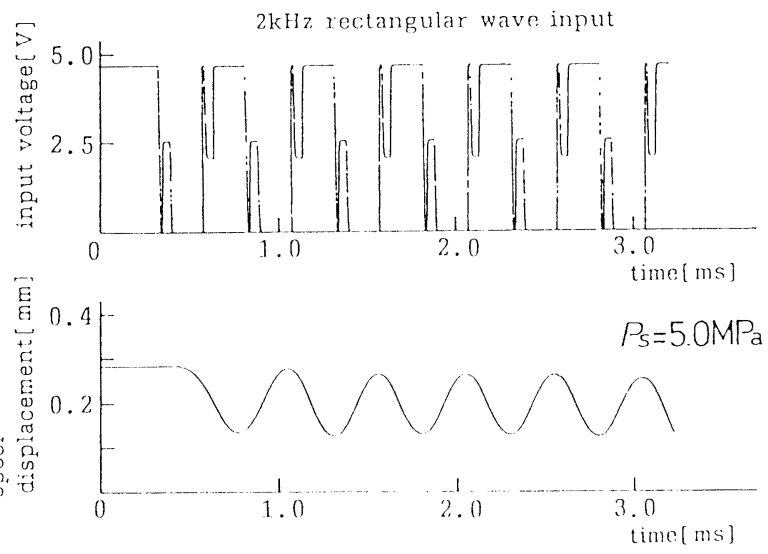

Fig.10 Recorded waveforms of spool displacement ( $2 \mathrm{kHz}$ rectangular wave input)
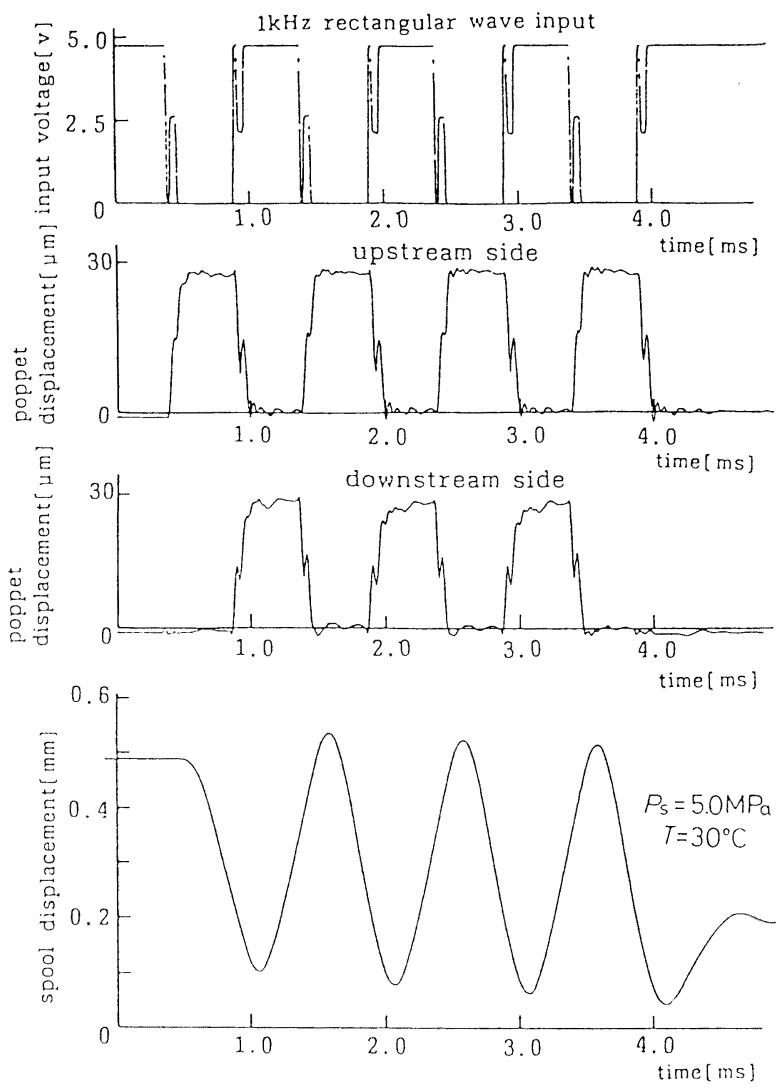

Fig.11 Recorded waveforms of spool displacement ( $1 \mathrm{kHz}$ rectangular wave input)

hydraulic transducer through I/O port. In this paper, subscript U denotes the supply side transducer, and subscript $\mathrm{D}$ denotes the drain side one.

The displacement of the spool is measured by a noncontact reluctance-type position sensor which responds accurately and quickly, and is fed to the system through A/D converter. We represents the states of a couple of the transducers in the following manner, according to bit states of the output valve I/O.

There are four combination of the states as shown in Fig.9. For example, the combination (b) in Fig.9 is represented as follows:

$$
(\mathrm{U}, \mathrm{D})=(1,0)
$$

The state denotes that the side $A$ of valve $\mathrm{U}$ is open and the side $\mathrm{A}$ of the valve $\mathrm{D}$ is closed, accordingly, the spool moves to the positive direction of $y$. In the same manner, the state of $(0,1)$ denotes the spool moves to the negative direction. The still state of the spool is realized by 


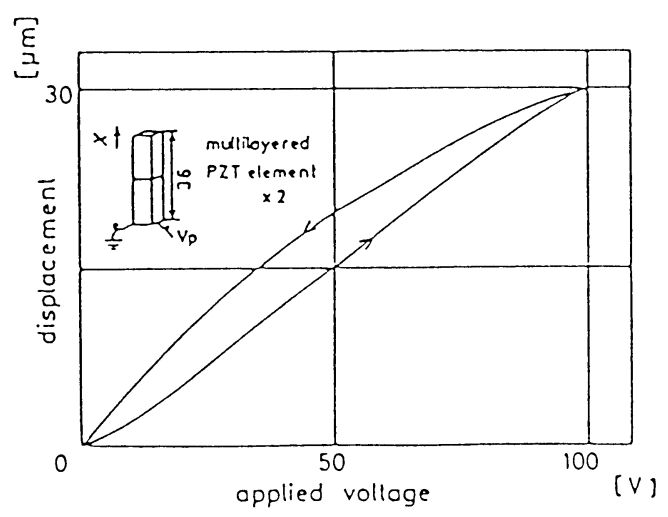

Fig.12 Static characteristics of a multilayered PZT element
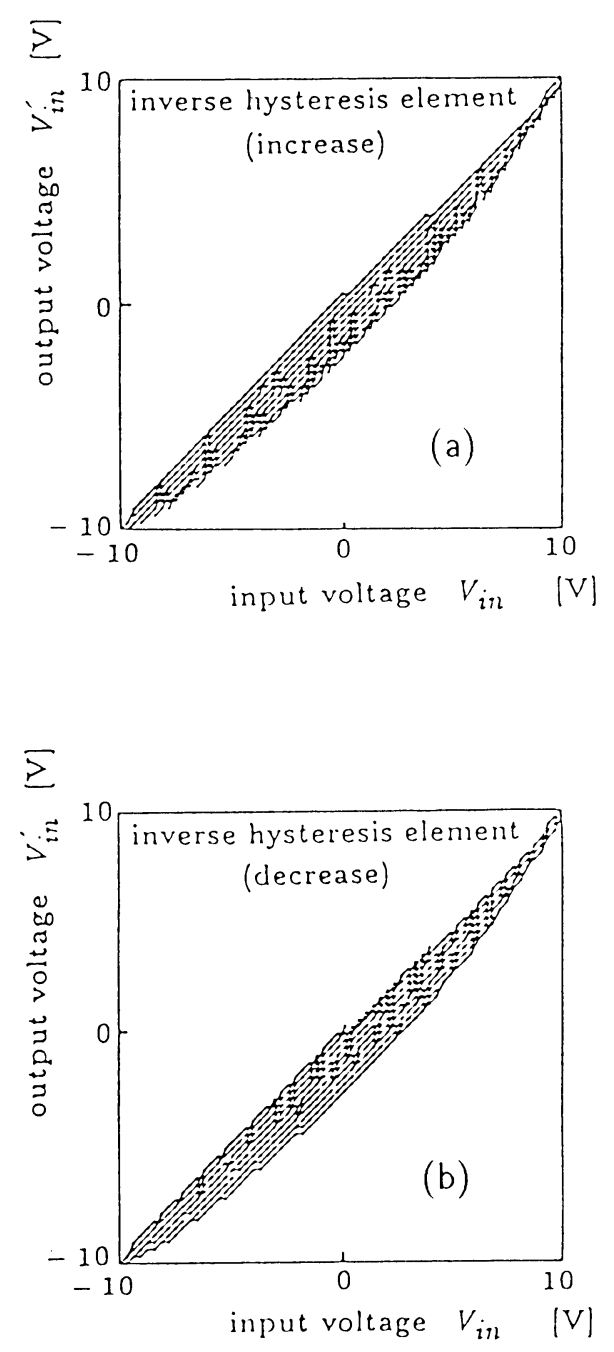

Fig.13 Inverse hysteresis maps two states of $(1,1)$ and $(0,0)$.

\section{Results of spool responses}

Figure 10 shows the results $y$ of the second stage spool when $2 \mathrm{kHz}$ rectangular wave input is applied to the first stage digital poppet valves. In this experiment, supply pressure is set at $5.0 \mathrm{MPa}$. It is ascertained that the spool responds to $2 \mathrm{kHz}$ input sinusoidally. In this case, the state of the poppets valve changes from initial $(0,0)$ to $(1,0)$ and $(0,1)$ by turns.

Figure 11 indicates experimental results of the spool and each poppet valve. In this experiment, a couple of the multilayered PZT elements is employed in series to obtain a larger poppet displacement of $30 \mu \mathrm{m}$. The results demonstrate that the amplitude of the spool displacement is about twice larger compared with the results in Fig.10.

\section{AN ULTRA HIGH-SPEED ELECTRO-HYDRAULIC SERVO VALVE}

\section{Hysteresis of a multilayered PZT element}

Figure 12 shows the static characteristics between applied voltage and output displacement of the PZT element. The elements have a comparatively large hysteresis characteristics between the applied voltage and the output displacement. The magnitude of the hysteresis is about $15 \%$ of the full scale.

The output wave forms are distorted and accompanied by delay (phase lag) due to the hysteresis characteristics, which is strongly dependent on the amplitude of the input. In applications for analog control of a servo-valve using PZT, it is desirable to remove the influence of the hysteresis. In this paper, we aim to realize an inverse hysteresis element expressed in a software algorithm on a microcomputer.

Realization of a high-speed inverse hysteresis element (IHE) operated in real time 

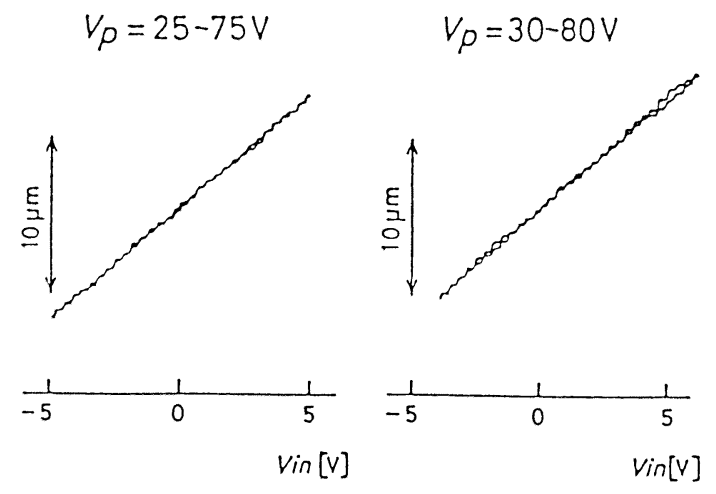

Fig.14 The effects of the inverse hysteresis element
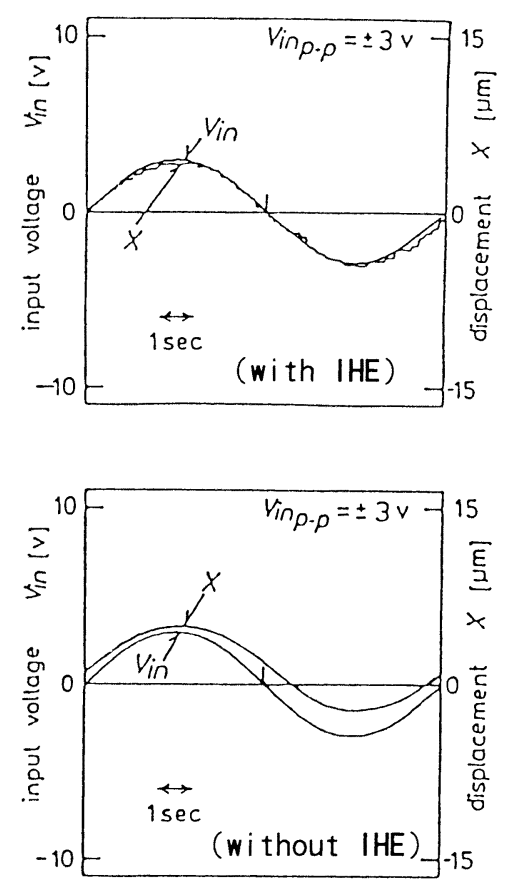

Fig.15 The effects of the inverse hysteresis element

The hysteresis model of the PZT element can be obtained by performing following procedure on a microcomputer system in consideration to realize high speed operation.

(1) to investigate the behavior or the motion of the PZT element precisely by experiment

(2) to realize a hysteresis model expressed in a software program based on the experimental results

(3) to obtain the inverse function model of the hysteresis by replacing input-output relation.

Figure 13 shows the inverse hysteresis maps, which are obtained by replacing each other with respect to the input and output of the hysteresis maps. It is noted that the path of a hysteresis element is much dependent on whether the input signal increases or decreases. Therefore, two different inverse hysteresis maps are needed which is referred to meet the cases as the input increases and decreases, as shown in Fig.13(a)(b), respectively. As for data discretization, the full scale of the input and output range is divided into 64 pieces (6bit).

In order to perform the processing in high speed and in real time, conversion tables on memories are prepared in advance to decide the next output of the inverse hysteresis element quickly and instantaneously. Using this tables, and employing an assemble language to describe the program, the required computing time can be reduced drastically. With respect to $\mathrm{A} / \mathrm{D}$ and D/A operating time, a high speed board ( $5 \mu$ s per one sampling ) is used.

By these means, a real time operating inverse hysteresis element (IHE) with the sampling frequency of $50 \mathrm{kHz}$ is realized. Figure 14 shows the results of the static characteristics. Figure 15 denotes the influence of input amplitude as sinusoidal input is applied to find the effect of the IHE. Applied bias voltage are maintained $50 \mathrm{~V}$. It is ascertained that using the IHE allows the successful removal of the nonlinearity due to the hysteresis for each input wave form.

\section{Construction of an ultra high-speed servo valve}

Figure 16 shows the schematic of the servo valve. The sleeve of the valve is employed from the commercially available servo valve (3F60L) made in Tokyo Seimitu Sokki corp. The diameter and the mass of the spool are $8.0 \mathrm{~mm}$ and $9.5 \times 10^{-3} \mathrm{~kg}$, respectively. Maximum flow rate through the orifice is $90 \mathrm{~cm}^{3} / \mathrm{s}(5.4 \mathrm{~L} / \mathrm{min})$ at $10 \mathrm{MPa}$ of pressure drop. The displacement of the spool is measured by non-contact reluctancetype position sensor which responds accurately and quickly, and is fed to the microcomputer system through $\Lambda / D$ converter. 


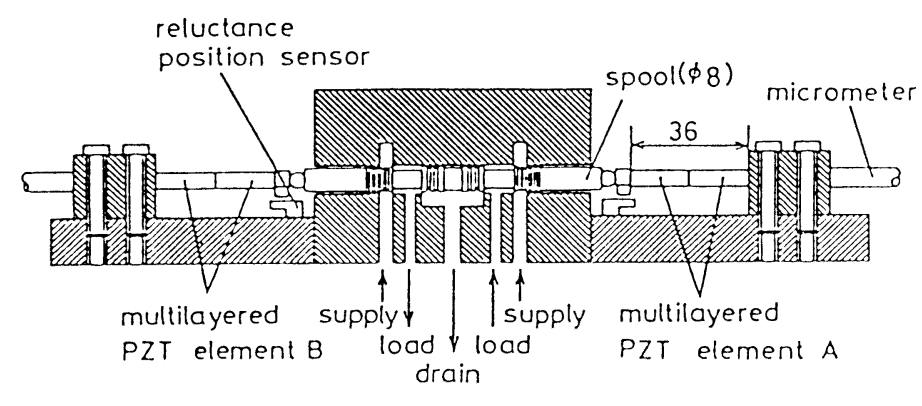

Fig.16 Schematic of the ultra high-speed servo-valve
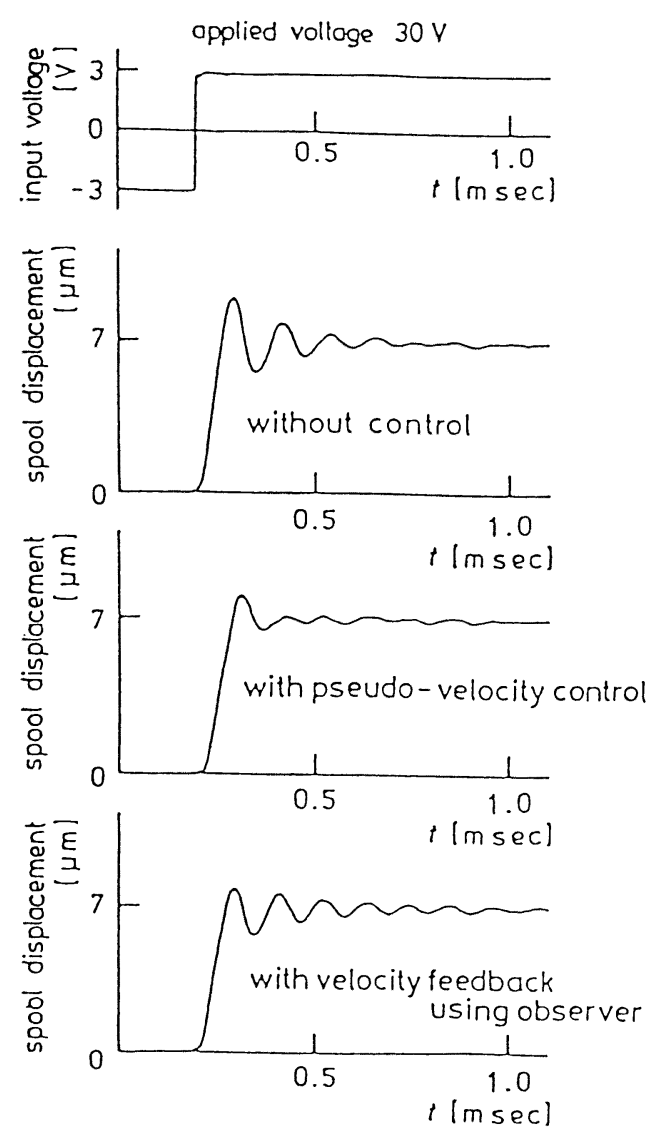

Fig.17 Step response of the spool displacement

The multilayered PZT elements are located at the both sides of the spool. The spool is connected through steel balls at both sides of the spool with the driving elements. The spool and the driving elements is pre-compressed by micro- meter head. In this case, the compression length by the pre-compression is set at $20 \mu \mathrm{m}$ based on our experimental results.

The valve dynamics and its improvement

The second wave form of Figure 17 shows the recorded wave forms of the spool displacement when a step input of $30 \mathrm{~V}$ is applied. The resonant frequency of the system is about $8.6 \mathrm{kHz}$. The spool displacement demonstrates very quick response, however, the results of the transient oscillation shows that the system damping is light and not adequate. This is a general problem in using the PZT element to drive an inertia load. As well as quick response, it is needed to add damping to the spool system which indicates an oscillatory transient response. The method to feedback the spool velocity can be easily recognized to add damping to the system. However, it is noted that the method is not always effective due to the hysteresis of the element and additional poles of the driving amplifier and so on.

In this paper, in order to have the damping heavier, following two methods are considered.

(1) velocity feed back control using an estimated spool velocity by Luenburger's observer. (2) pseudo-velocity feed forward control using pseudo-velocity obtained from a second-order linear model of the system.

\section{Estimation of the spool velocity using an observer}

The relationship between driving force and displacement of the PZT elements is approximated as a second order system shown in Fig.17. The resonant frequency and the damping ratio are determined $8.6 \mathrm{kIIz}$ and 0.22 respectively, based on the step response.

\section{Pseudo-velocity feed forward control}

A velocity signal from the second order model is obtained as output shown in Fig.18. The signal is called as pseudo-velocity. We try to feed the pseudo-velocity forward the system as shown in Fig.18, to add damping to the system. In this method, phase lead effect is ex- 
pected, compared to the method of vclocity feed back with phase lag elements, because the influence of phase lag duc to the hysteresis and poles of amplifier can be avoided.

\section{Expcrimental results}

Figure 17 shows the recorded wave forms of the spool displacement as a step input of $30 \mathrm{~V}$. The top wave form indicates input signal. The second one shows the spool displacement without control. The third one denotes the spool response with the pseudo-vclocity fecd forward control. Bottom one denotes the spool displacement with the velocity feed back control. Figure 17 demonstrates that it is possible to add adequate damping to the spool system as well as quick response, using the pscudo-velocity feed forward control. On the other hand, in velocity feed back control, although the overshoot is a little reduced, the system damping gets rather worse. It is considered due to the additional phase lag elements such as hysteresis, poles of the amplifier in the closed loop.

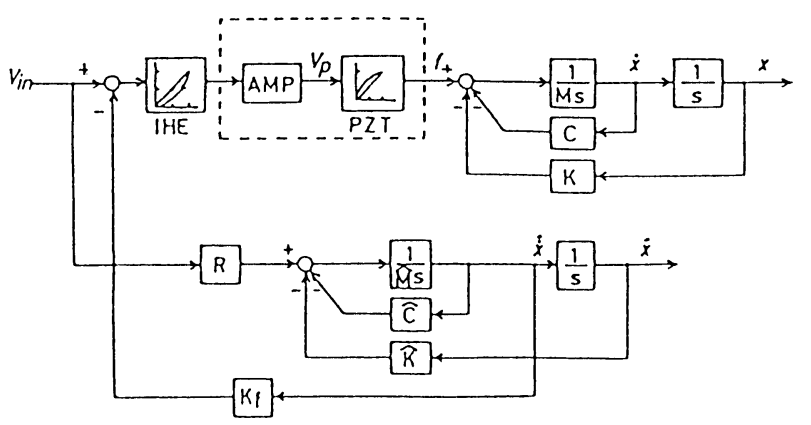

Fig.18 Block diagram

( feed forward control)

\section{CONCLUSIONS}

Firstly a fast-acting digital electrohydraulic transducer is developed which is composed of two poppet-type on-off valves which are coaxially opposed. The valve is directly driven using multilayered PZT elements. A kind of feed forward control is introduced in order to obtain high speed response, to provide sufficient damping characteristics, and to improve the effect due to the load pressure adding a pressure cancelers. As a result, the driving system is successfully ascertained to have $7.0 \mathrm{kHz}$ of the eigen frequency of the valve with the pressure cancelers. Also, the valve may responds to $2 \mathrm{kHz}$ rectangular wave input.

In its application, the response of a digital input two stage servo valve is investigated using a couple of the transducers as a first stage to drive a second stage spool valve.

Secondly, an ultra high-speed servo-valve is developed, which is directly driven using multilayered PZT elements. An inverse hysteresis element (IHE) is introduced to remove the hysteresis of the PZT elements, which operate in real time at the sampling frequency of $50 \mathrm{kHz}$. Also a feed forward control is introduced in order to obtain high speed response and to provide sufficient damping characteristics. As a result, a servo valve with the bandwidth over $5 \mathrm{kHz}$ is successfully developed.

\section{REFERENCES}

(1) Tanaka, H., Electrohydraulic digital servo mechanism by the pulse flow control, Proc. of The 1st FLUCOME, Tokyo, (1985) p.429.

(2) Lühmann, B., Electro-hydraulischer stellentrieb mit Abtastregelung einsatzeines mikrorechners, Aahener Fluidtechnisches Kolloquim, (1982)

(3) Ohuchi, H., Nakano, K. and Endou, H., High-speed electrohydraulic servovalves using electrostrictive ceramic PMN actuators, Proc. of The 1st FLUCONE, Tokyo, (1985) p.415. 
(4) Ikebe, Y. and Nakada, T., On a piezoclectric flapper-type servovalves operated by a pulse-width modulated signal, Trans. ASME, 88, J. of DSMC, (1974).

(5) Yokota,S., Kondou,Y., Akutu,K. : An Ultra Fast-Acting Electro-Hydraulic Digital Valve by Making Use of Multilayered Piezo-Electric Device (PZT),

The 3rd FLUCOME Conference, SanFrancisco, pp379-384, (1991)

(6) Yokota,S., Hiramoto,K.: An Ultra High-Speed Electro-Hydraulic Servo Valve by Making Use of Multilayered Piezo-Electric Device (PZT),

The International Symposium on Fluid Power \& Transmission Control, Beijing, pp29-33, (1991)

(7)Yokota,S., Akutu,K. : A Fast-Acting Electro-Hydraulic Transducer (A Poppet-type On-Off

Digital Valve Using Multilayered Piezo-Electric Device (PZT), JSME International Journal,

Vol.34,(Ser.II), No.4, p489 495, (1991) 